\title{
ANALISA FUNGSI KARAKTERISTIK SEBAGAI PENCIRI DISTRIBUSI PELUANG
}

\author{
Alona Dwinata \\ alonadwinata@gmail.com \\ Pendidikan Matematika - FKIP Universitas Maritim Raja Ali Haji \\ 2016
}

\begin{abstract}
Abstrak
Fungsi karakteristik dari sebuah peubah acak mempunyai peranan penting dalam mengkaji kekonvergenan suatu fungsi distribusi. Salah satu teorema penting dalam kekonvergenan suatu fungsi distribusi adalah Teorema Limit Pusat Le'vy. Teorema Limit Pusat Le`vy menjelaskan bahwa jumlah dari peubah acak yang saling bebas, berdistribusi identik, dan mempunyai variansi akan mendekati distribusi Normal untuk $n$ yang cukup besar. Jika $\left(\varphi_{n}\right)$ merupakan barisan fungsi karakteristik dari barisan fungsi distribusi $\left(F_{n}\right)$ yang saling bebas dan berdistribusi identik dan $\varphi$ merupakan fungsi karakteristik dari fungsi distribusi $F$, maka apakah jika barisan $\left(F_{n}\right)$ konvergen ke $F$ akan diikuti kekonvergenan $\left(\varphi_{n}\right)$ ke $\varphi$ ?. Berdasarkan kajian pustaka diperoleh jawaban bahwa kekonvergenan barisan fungsi distribusi $\left(F_{n}\right)$ ke fungsi distribusi $F$ akan diikuti kekonvergenan $\left(\varphi_{n}\right)$ ke $\varphi$ dengan syarat:
\end{abstract}

i. $\quad F_{n} \stackrel{c}{\rightarrow} F$

ii. $\varphi$ kontinu pada $t=0$

syarat perlu

syarat cukup.

Kata Kunci: distribution function, fungsi karakteristik, kekonvergenan

Characteristics function from a random variable has a crucial role in examining the convergence of a particular distribution function. One of important theorems in convergence of a distribution function is theorem of Le'vy's central limit. It implies that sum of some independently random variables, identically distributed, and having variance, will approach normal distribution for great enough value of $n$. Given $\left(\varphi_{n}\right)$ as series of characteristics function from series of distribution function $\left(F_{n}\right)$ which is independent each other and identically distributed and $\varphi$ as characteristics function of distribution function $\mathrm{F}$, then if given series $\left(F_{n}\right)$ convergent to $\mathrm{F}$, will it be implied by convergence of $\left(\varphi_{n}\right)$ to $\varphi$ ?. Based on literature study, it is obtained that the convergence of series of distribution function $\left(F_{n}\right)$ to distribution function $\mathrm{F}$ will be followed by the convergence of $\left(\varphi_{n}\right)$ to $\varphi$ under these following conditions:
i. $\quad F_{n} \stackrel{c}{\rightarrow} F$
necessary condition
ii. $\varphi$ kontinu pada $t=0$
sufficient condition.

Keywords: distribution function, characteristics function, convergence

\section{Pendahuluan}

\section{Latar Belakang}

Salah satu konsep dasar dalam statistika adalah distribusi peluang. Distribusi peluang merupakan model matematika yang diperoleh dari sebagian data pada keseluruhan data yang menjadi perhatian dalam suatu percobaan di sebuah populasi. Oleh sebab itu secara teori distribusi peluang dapat menjelaskan prilaku dari populasi tersebut.

Setiap distribusi peluang memiliki ciri khas masing - masing. Ciri dari sebuah distribusi peluang ini dapat dilihat dari fungsi pembangkit momen. Menurut Bean (2001: 156) "Fungsi pembangkit momen 
merupakan alat yang sangat berguna untuk menunjukkan distribusi dari sebuah peubah acak". Jadi, fungsi pembangkit momen merupakan penciri dari sebuah distribusi peluang.

Perluasan fungsi pembangkit momen adalah fungsi karakteristik, karena fungsi pembangkit momen hanya terbatas pada bilangan riil saja. Hogg \& Craig (2004:64) menyatakan bahwa "banyak distribusi peluang yang tidak memiliki fungsi pembangkit momen tetapi fungsi karakteristiknya selalu ada”. Dengan demikian, fungsi karakteristik merupakan penciri dari sebuah distribusi peluang. Jadi, jika diketahui fungsi karakteristik dari suatu distribusi, maka dapat diketahui fungsi distribusinya. Dengan kata lain, fungsi karakteristik dapat menunjukkan distribusi dari sebuah peubah acak. Hogg \& Craig (2004: 64) juga menegaskan bahwa "Setiap distribusi peluang memiliki fungsi karakteristik yang unik". Hal ini berarti, fungsi karakteristik yang menunjukkan suatu distribusi adalah tunggal.

Bhat (1981: 91) menyatakan "Fungsi karakteristik dari sebuah peubah acak memiliki peranan penting dalam mengkaji kekonvergenan suatu fungsi ditsribusi". Jadi sebagai penciri sebuah fungsi distribusi, fungsi karakteristik juga dapat menunjukkan kekonvergenan dari sebuah fungsi distribusi.

Salah satu teorema penting dalam mengkaji kekonvergenan suatu fungsi distribusi adalah Teorema Limit Pusat Le`vy. Le`vy menyatakan (Laha \& Rohatgi, 1979: 287) "Jika $X_{1}, X_{2}, \ldots, X_{n}$ merupakan peubah acak yang saling bebas dan berdistribusi identik dengan $0<\operatorname{var}\left(X_{n}\right)=\sigma^{2}<\infty$, $S_{n}=\sum_{k=1}^{n} X_{k}$ maka untuk setiap $X \in \mathbf{R}$

$$
\lim _{n \rightarrow \infty} P\left\{\frac{\left(S_{n}-E\left[S_{n}\right]\right)}{\sigma \sqrt{n}} \leq x\right\}=\frac{1}{\sqrt{2 \pi}} \int_{-\infty}^{x} e^{-u^{2} / 2} d u
$$

Teorema Limit Pusat Le`vy ini menjelaskan bahwa jumlah dari peubah acak yang saling bebas dan berdistribusi identik, dan jika masing - masing variansinya ada maka jumlah peubah acak tersebut akan mendekati distribusi Normal untuk $n$ yang cukup besar. Akibatnya, dengan menggunakan Teorema Limit Pusat Le`vy tidak perlu lagi melakukan uji kenormalan, jika dipenuhi kondisi - kondisi tersebut.

Berdasarkan Teorema Limit Pusat Le`vy di atas, suatu barisan peubah acak yang berdistribusi Poisson dan saling bebas untuk $n$ yang cukup besar tentulah akan konvergen ke distribusi Normal. Menurut Laha \& Rohatgi (1979: 232).

Fungsi karakteristik dari peubah acak berdistribusi Poisson adalah $\varphi(t)=e^{\left\{\lambda\left(e^{i t}-1\right)\right\}} ; \lambda>0$ dan fungsi karakteristik dari barisan peubah acak yang berdistribusi Poisson adalah $\varphi_{n}(t)=e^{\left\{\frac{\lambda}{n}\left(e^{i t}-1\right)\right\}} ; \lambda>$ 0 , sedangkan fungsi karakteristik dari peubah acak yang berdistribusi Normal adalah $\varphi(t)=e^{i \theta t-\sigma^{2} t^{2} / 2}$; $\sigma>0$ dan fungsi karakteristik dari barisan peubah acak yang berdistribusi Normal adalah

$$
\varphi_{n}(t)=e^{i \frac{\theta}{n} t-\frac{\sigma^{2} t^{2}}{n^{2}}} ; \sigma>0
$$

Sebagai fungsi penciri dari sebuah distribusi, apakah $\left(\varphi_{n}\right)$ yang berdistribusi Poisson juga akan konvergen ke $\varphi$ yang berdistribusi Normal untuk jumlah $n$ yang cukup besar. Dengan kata lain, jika $\left(P_{n}\right)$ adalah suatu barisan fungsi yang berdistribusi Poisson dengan barisan fungsi karakteristiknya $\left(\varphi_{n}\right)$ dan $N$ adalah sebuah fungsi yang berdistribusi Normal dengan fungsi karakteristik $\varphi$, maka menurut Teorema Limit Pusat Le`vy barisan fungsi yang berdistribusi Poisson konvergen ke fungsi yang berdistribusi Normal. Sebagai penciri suatu distribusi peluang, apakah barisan fungsi karakteristik yang berdistribusi Poisson juga konvergen ke fungsi karakteristik yang berdistribusi Normal?

Berdasarkan hal di atas, fungsi karakteristik mempunyai peranan penting dalam mengkaji kekonvergenan suatu fungsi distribusi. Oleh karena itu, penulis tertarik untuk mengetahui apa syarat perlu 
dan syarat cukup agar jika $\left(\varphi_{n}\right)$ merupakan barisan fungsi karakteristik dari barisan fungsi distribusi $\left(F_{n}\right)$ dan $\varphi$ merupakan fungsi karakteristik dari fungsi distribusi $F$, maka $\left(\varphi_{n}\right)$ akan konvergen ke $\varphi$, dimana $\left(F_{n}\right)$ konvergen ke $F$. Untuk itu tulisan ini penulis beri judul "Kekonvergenan Fungsi Karakteristik".

\section{Rumusan Masalah}

Misalkan barisan fungsi distribusi $\left(F_{n}\right)$ konvergen ke suatu fungsi distribusi $F$. Misalkan $\left(\varphi_{n}\right)$ merupakan barisan fungsi karakteristik dari $\left(F_{n}\right)$ dan $\varphi$ merupakan fungsi karakteristik dari $F$. Perumusan masalah dalam penelitian ini adalah apakah syarat perlu dan syarat cukup agar barisan fungsi karakteristik $\left(\varphi_{n}\right)$ konvergen $\operatorname{ke} \varphi$ ?

\section{Tujuan Penelitian}

Penelitian ini bertujuan untuk mengetahui syarat perlu dan syarat cukup agar kekonvergenan barisan fungsi distribusi $\left(F_{n}\right)$ ke $F$ akan diikuti pula oleh kekonvergenan barisan fungsi karakteristik $\left(\varphi_{n}\right)$ ke $\varphi$, dimana $\left(\varphi_{n}\right)$ merupakan barisan fungsi karakteristik dari $\left(F_{n}\right)$ dan $\varphi$ merupakan fungsi karakteristik dari $F$.

\section{Metodologi Penelitian}

Penelitian ini merupakan penelitian teoritis. Metode yang digunakan adalah metode deskriptif dengan analisis teori yang relevan dengan permasalahan yang dibahas dan berlandaskan pada studi kepustakaan. Dalam melakukan penelitian ini, penulis memulai dengan meninjau permasalahan, mengumpulkan dan mengaitkan teori-teori yang didapat dengan permasalahan yang dihadapi sebagai penunjang untuk menjawab permasalahan.

Adapun langkah - langkah yang penulis lakukan untuk menjawab permasalahan adalah sebagai berikut.

1. Menelaah dari beberapa sumber tentang kekonvergenan fungsi distribusi.

2. Mengkaji tentang barisan fungsi distribusi.

3. Mengkaji tentang barisan fungsi karakteristik.

4. Mengaitkan antara kekonvergenan fungsi distribusi dengan kekonvergenan fungsi karakteristik dengan mengacu pada kekonvergenan yang ada pada distribusi.

5. Membuktikan hasil analisis tentang kekonvergenan fungsi karakteristik.

\section{Pembahasan}

Berikut ini diberikan beberapa teorema kekonvergenan fungsi distribusi yang dikutip dari beberapa sumber yang berbeda sebagai berikut :

1. Feller (1977: 481)

Sebuah barisan fungsi distribusi $\left(F_{n}\right)$ konvergen ke sebuah fungsi distribusi $F$ jika dan hanya jika barisan $\left(\varphi_{n}\right)$ dari fungsi karakteristiknya konvergen ke sebuah limit $\varphi$ kontinu. Dalam hal ini $\varphi$ adalah fungsi karakteristik dari $F$, dan kekonvergenan $\varphi_{n} \rightarrow \varphi$ adalah seragam disetiap interval hingga.

2. Laha \& Rohatgi (1979: 153)

Misalkan $\left(F_{n}\right)$ adalah sebuah barisan fungsi distribusi dan $\left(\varphi_{n}\right)$ adalah barisan fungsi karakteristik dari $\left(F_{n}\right)$, maka $\left(F_{n}\right)$ konvergen lengkap ke sebuah fungsi distribusi $F$ jika dan hanya jika $\varphi_{n} \rightarrow \varphi$ untuk $n \rightarrow \infty$ di $\mathbb{R}$, dimana $\varphi$ kontinu pada $t=0$. Dalam hal ini limit fungsi $\varphi$ adalah fungsi karakteristik dari limit fungsi distribusi $F$.

3. Bhat (1981: 158)

Jika $F_{n} \stackrel{c}{\rightarrow} F$ maka $\varphi_{n} \rightarrow \varphi$, sebaliknya jika $\varphi_{n} \rightarrow \psi$, kontinu pada $u=0$ maka $F_{n} \stackrel{c}{\rightarrow} F$ dan $\varphi=\psi$.

4. Cassela \& Berger $(2002: 84)$

Jika Barisan peubah acak $\left(X_{k}\right) ; k=1,2,3, \ldots$ dengan masing - masing fungsi karakteristiknya $\varphi_{X_{k}}(t)$ dan $\lim _{k \rightarrow \infty} \varphi_{X_{k}}(t)=\varphi_{X}(t)$ untuk semua $\mathrm{t}$ maka $\lim _{k \rightarrow \infty} F_{X_{k}}(x)=F_{X}(x)$ untuk semua $X$ dengan $F_{X}(x)$ adalah kontinu 
Berdasarkan keempat sumber di atas, dapat dilakukan analisis pada masing - masing sumber sebagai berikut.

1. Feller (1977: 481)

Karena $\left(F_{n}\right)$ merupakan barisan fungsi distribusi dari peubah acak $\left(X_{n}\right)$ dan $F$ merupakan fungsi distribusi dari peubah acak $X$, maka $\left(X_{n}\right)$ konvergen dalam distribusi ke $X$. Berdasarkan definisi kekonvergenan dalam distribusi maka tentulah $F_{n} \stackrel{c}{\rightarrow} F$.

2. Laha \& Rohatgi $(1979: 153)$

Pada sumber ini, $\left(F_{n}\right)$ konvergen lengkap ke sebuah fungsi distribusi $F$. Hal ini dapat ditulis, $F_{n} \stackrel{c}{\rightarrow} F$.

3. Bhat $(1981: 158)$

Menurut sumber ini, jelas ditulis bahwa $F_{n} \stackrel{c}{\rightarrow} F$.

4. Cassela \& Berger $(2002: 84)$

Menurut definisi kekonvergenan, $\left(F_{X_{k}}\right)$ konvergen lengkap ke sebuah fungsi distribusi $F_{X}$. Hal ini berarti, $F_{n} \stackrel{c}{\rightarrow} F$.

Dari keempat pendapat di atas, dapat diambil kesimpulan bahwa jika $\left(\varphi_{n}\right)$ merupakan fungsi karakteristik dari $\left(F_{n}\right)$ dan $\varphi$ merupakan fungsi karakteristik dari $F$, maka syarat yang harus dipenuhi agar suatu barisan fungsi karakteristik $\left(\varphi_{n}\right)$ konvergen ke fungsi karakteristik $\varphi$ adalah :
i. $\quad F_{n} \stackrel{c}{\rightarrow} F$
syarat perlu
ii. $\varphi$ kontinu pada $t=0$
syarat cukup.

Atau, dalam pernyataan "Misalkan $\left(F_{n}\right)$ adalah sebuah barisan fungsi distribusi dengan $\left(\varphi_{n}\right)$ adalah barisan fungsi karakteristik dari $\left(F_{n}\right)$ dan $F$ adalah sebuah fungsi distribusi dengan $\varphi$ adalah fungsi karakteristik dari $F$, maka $F_{n} \stackrel{c}{\rightarrow} F$ jika dan hanya jika $\varphi_{n} \rightarrow \varphi$ untuk $n \rightarrow \infty$ di $\mathbb{R}$, dimana $\varphi$ kontinu pada $t=0$ ".

Adapun buktinya adalah sebagai berikut.

$(\Longrightarrow) \quad$ Anggap $F_{n} \stackrel{c}{\rightarrow} F$, dengan $\left(F_{n}\right)$ adalah suatu barisan fungsi distribusi dan $F$ adalah suatu fungsi distribusi. Menurut definisi fungsi karakteristik, $\left(F_{n}\right)$ dan $F$ masing - masingnya memiliki fungsi karakteristik

$$
\begin{aligned}
& \varphi_{n}(t)=\int_{R} e^{i t x} d F_{n}(x)=\int_{R}(\cos t x+i \sin t x) d F_{n}(x) \\
& \varphi(t)=\int_{R} e^{i t x} d F(x)=\int_{R}(\cos t x+i \sin t x) d F(x) .
\end{aligned}
$$

Karena $F_{n} \stackrel{c}{\rightarrow} F$ maka berdasarkan teorema dibawah ini :

"Misalkan $g$ fungsi kontinu bernilai riil terbatas pada $\mathbb{R}$, dan $\left(h_{n}\right)$ adalah barisan fungsi terbatas seragam, tak turun dan kontinu kanan yang konvergen lengkap ke suatu fungsi $h$ di $\mathbb{R}$, maka

$$
\lim _{n \rightarrow \infty} \int_{-\infty}^{\infty} g d h_{n}=\int_{-\infty}^{\infty} g d h \text { “. (Laha \& Rohatgi, 1979: }
$$

untuk setiap $t \in \mathbb{R}$ diperoleh

$$
\begin{aligned}
& \int_{\mathbf{R}} \cos t x d F_{n}(x) \rightarrow \int_{\mathbf{R}} \cos t x d F(x) \\
& \text { dan } \\
& \int_{R} \sin t x d F_{n}(x) \rightarrow \int_{\mathbf{R}} \sin t x d F(x)
\end{aligned}
$$


maka

$$
\begin{aligned}
& \int_{\mathbf{R}} e^{i t x} d F_{n}(x) \rightarrow \int_{\mathbf{R}} e^{i t x} d F(x), \text { dan } \int_{\mathbf{R}} e^{i t x} d F(x) \text { kontinu pada } t=0 . \\
& \varphi_{n}(t) \rightarrow \varphi(t) \quad, \forall t \in \mathbb{R} \quad \text { untuk } n \rightarrow \infty \text { Jadi, jika } F_{n} \stackrel{c}{\rightarrow} F \text { maka } \varphi_{n}(t) \rightarrow \varphi(t) \quad, \forall t \in
\end{aligned}
$$

$\mathbb{R} \quad$ untuk $n \rightarrow \infty$.

$(\Longrightarrow)$ Sebaliknya, anggap $\varphi_{n} \rightarrow \varphi$ pada $\mathbb{R}$, dan $\varphi$ kontinu pada $t=0$. Jika $F$ adalah sebuah fungsi distribusi dengan fungsi karakteristik $\varphi$, maka $\forall h>0$ berlaku persamaan berikut :

$$
\int_{0}^{h} F(y) d y-\int_{-h}^{0} F(y) d y=\frac{1}{\pi} \int_{-\infty}^{\infty} \frac{1-\cos h t}{t^{2}} \varphi(t) d t
$$

Untuk membuktikan persamaan (1), misalkan $a>0$, G merupakan distribusi seragam dari fungsi $g$ pada $[-a, a]$ dengan pendefinisian

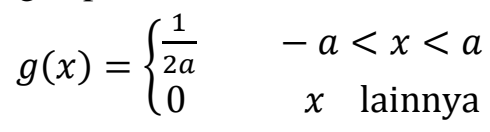

dengan fungsi karakteristik dari $g(x)$

$$
\begin{aligned}
\theta(t)=\int_{-a}^{a} \frac{1}{2 a} e^{i t x} d x & =\frac{1}{2 a} \int_{-a}^{a} e^{i t x} d x \\
& =\frac{1}{2 a}\left[\frac{1}{i t} e^{i t x}\right]_{-a}^{a} \\
& =\frac{1}{2 a}\left[\frac{e^{i t a}-e^{-i t a}}{i t}\right] \\
& =\frac{1}{a t}\left[\frac{e^{i t a}-e^{-i t a}}{2 i}\right] \\
& =\frac{1}{a t} \sin a t \\
& =\frac{\sin a t}{a t} .
\end{aligned}
$$

Anggap fungsi distribusi $\mathrm{H}=\mathrm{F} * \mathrm{G}$, jadi $\mathrm{H}$ kontinu di $\mathbb{R}$ yaitu

$$
H(x)=\frac{1}{2 a} \int_{x-a}^{x+a} F(y) d y \text {. }
$$

Misalkan $\psi$ fungsi karakteristik dari $\mathrm{H}$, maka berdasarkan teorema konvolusi

"Misalkan $F, F_{1}, F_{2}$ adalah tiga fungsi distribusi dengan fungsi karakteristiknya masing - masing adalah $\varphi, \varphi_{1}, \varphi_{2}$, maka

$$
\begin{aligned}
F=F_{1} * F_{2} & \Leftrightarrow \varphi=\varphi_{1} \varphi_{2} . "(\text { Laha \& Rohatgi, 1979: 150) diperoleh } \\
\psi(t) & =\varphi(t) \theta(t)=\varphi(t) \frac{\sin a t}{a t} .
\end{aligned}
$$

Dengan menggunakan teorema inversi untuk $\mathrm{H}$ dan $\psi$

"Misalkan $F$ adalah sebuah fungsi distribusi dan $\varphi$ adalah sebuah fungsi karakteristik, maka

$$
F(a+h)-F(a-h)=\lim _{T \rightarrow \infty} \frac{1}{\pi} \int_{-T}^{T} \frac{\sin h t}{t} e^{-i t a} \varphi(t) d t,
$$


JURNAL GANTANG Pendidikan Matematika FKIP - UMRAH

Vol. 1 No. 1, Agustus 2016, p-ISSN. 2503-0671, e-ISSN. 2548-5547

dengan $a \in \mathbb{R}$ dan $h>0$.

(Laha \& Rohatgi, 1979: 144)

sehingga diperoleh

$$
\begin{array}{r}
H(x+a)-H(x-a)=\lim _{T \rightarrow \infty} \frac{1}{\pi} \int_{-T}^{T} \frac{\sin a t}{t} e^{-i t x} \varphi(t) \frac{\sin a t}{a t} d t \\
H(x+a)-H(x-a)=\lim _{T \rightarrow \infty} \frac{1}{\pi} \int_{-T}^{T} \frac{\sin ^{2} a t}{a t^{2}} e^{-i t x} \varphi(t) d t \\
=\frac{1}{\pi} \int_{-\infty}^{\infty} \frac{2 \sin ^{2} a t}{2 a t^{2}} e^{-i t x} \varphi(t) d t \\
=\frac{1}{2 \pi a} \int_{-\infty}^{\infty} \frac{1-\cos 2 a t}{t^{2}} e^{-i t x} \varphi(t) d t
\end{array}
$$

Khusus untuk $x=0$, diperoleh

$$
H(a)-H(-a)=\frac{1}{2 \pi a} \int_{-\infty}^{\infty} \frac{1-\cos 2 a t}{t^{2}} \varphi(t) d t
$$

dengan mensubstitusikan persamaan

$$
\begin{aligned}
& H(a)-H(-a)=\frac{1}{2 \pi a} \int_{-\infty}^{\infty} \frac{1-\cos 2 a t}{t^{2}} \varphi(t) d t \\
& \frac{1}{2 a} \int_{0}^{2 a} F(y) d y-\frac{1}{2 a} \int_{-2 a}^{0} F(y) d y=\frac{1}{2 \pi a} \int_{-\infty}^{\infty} \frac{1-\cos 2 a t}{t^{2}} \varphi(t) d t \\
& \frac{1}{2 a} \int_{0}^{2 a} F(y) d y-\frac{1}{2 a} \int_{-2 a}^{0} F(y) d y=\frac{1}{2 \pi a} \int_{-\infty}^{\infty} \frac{1-\cos 2 a t}{t^{2}} \varphi(t) d t \\
& \frac{1}{2 a}\left(\int_{0}^{2 a} F(y) d y-\int_{-2 a}^{0} F(y) d y\right)=\frac{1}{2 \pi a} \int_{-\infty}^{\infty} \frac{1-\cos 2 a t}{t^{2}} \varphi(t) d t
\end{aligned}
$$

pada persamaan

(3) diperoleh

dengan mengganti nilai $2 a=h$ diperoleh persamaan (1)

$\int_{0}^{h} F(y) d y-\int_{-h}^{0} F(y) d y=\frac{1}{\pi} \int_{-\infty}^{\infty} \frac{1-\cos h t}{t^{2}} \varphi(t) d t$.

Jadi, $F$ merupakan fungsi distribusi.

Karena $\left(F_{n}\right)$ merupakan barisan fungsi distribusi, berdasarkan teorema Helly

"Misalkan $\left(g_{n}\right)$ sebuah barisan fungsi terbatas seragam, tak turun dan kontinu kanan, maka terdapat sebuah subbarisan $\left(g_{n k}\right)$ dari $\left(g_{n}\right)$ yang konvergen lemah ke fungsi terbatas, tak turun dan kontinu kanan."(Laha \& Rohatgi, 1979: 133)

maka ada sebuah subbarisan $\left(F_{n k}\right)$ dari $\left(F_{n}\right)$ yang konvergen lemah ke suatu fungsi $F$ terbatas, tidak turun dan kontinu kanan, atau ditulis $F_{n k} \stackrel{w}{\rightarrow} F$.

Sekarang akan dibuktikan bahwa $F$ adalah fungsi distribusi. Berdasarkan persamaan (1) diperoleh:

$$
\int_{0}^{h} F_{n k}(y) d y-\int_{-h}^{0} F_{n k}(y) d y=\frac{1}{\pi} \int_{-\infty}^{\infty} \frac{1-\cos h t}{t^{2}} \varphi_{n k}(t) d t \quad ; \forall h>0
$$


Karena $F_{n k} \stackrel{w}{\rightarrow} F$ maka

$\int F_{n k}(y) d y \rightarrow \int F(y) d y$.

Akibatnya,

$\int_{0}^{h} F(y) d y-\int_{-h}^{0} F(y) d y=\frac{1}{\pi} \int_{-\infty}^{\infty} \frac{1-\cos h t}{t^{2}} \varphi(t) d t$

pembagian kedua sisi dengan $h$,

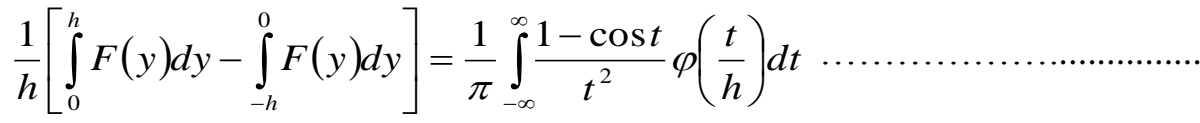

dengan $\varphi$ kontinu pada $\mathrm{t}=0$, diperoleh

$\lim _{h \rightarrow \infty} \varphi\left(\frac{t}{h}\right)=\varphi(0)=\lim _{n \rightarrow \infty} \varphi_{n}(0)=1$

$\frac{1}{h}\left[\int_{0}^{h} F(y) d y-\int_{-h}^{0} F(y) d y\right]=\frac{1}{\pi} \int_{-\infty}^{\infty} \frac{1-\cos t}{t^{2}}(1) d t$

Misalkan $h \rightarrow \infty$ dalam persamaan (5) diperoleh:

$F(+\infty)-F(-\infty)=\frac{1}{\pi} \int_{-\infty}^{\infty} \frac{1-\cos t}{t^{2}} d t=1$

Karena $0 \leq F \leq 1, F(-\infty)=0$ dan $F(+\infty)=1$, maka $F$ adalah fungsi distribusi. Jadi, $\varphi$ merupakan fungsi karakteristik dari suatu fungsi distribusi $F$.

Anggap $F_{n}$ terdiri dari subbarisan lain yang konvergen ke sebuah limit $F^{*}$ maka $F^{*}$ adalah sebuah fungsi distribusi dengan fungsi karakteristik $\varphi$. Dengan teorema ketunggalan $F=F^{*}$, yang mana secara tidak langsung setiap subbarisan $\left(F_{n}\right)$ mempunyai limit yang sama dengan $F$. Jadi, $F_{n} \stackrel{c}{\rightarrow} F$ dengan $\varphi$ adalah fungsi karakteristik dari $F$. Dengan kata lain, jika $\varphi_{n} \rightarrow \varphi$ pada $\mathbb{R}$ dan $\varphi$ kontinu pada $t=0$, maka $F_{n}$ $\stackrel{c}{\rightarrow} F$.

\section{Kesimpulan}

Misal $F_{n}$ adalah sebuah barisan fungsi distribusi dengan fungsi karakteristik $\varphi_{n}$ dan $F$ adalah sebuah fungsi distribusi dengan fungsi karakteristik $\varphi$. Maka $\varphi_{n} \rightarrow \varphi$ jika dan hanya jika memenuhi syarat berikut:
i. $\quad F_{n} \stackrel{c}{\rightarrow} F$
syarat perlu
ii. $\varphi$ kontinu pada $t=0$
syarat cukup 
JURNAL GANTANG Pendidikan Matematika FKIP - UMRAH

Vol. 1 No. 1, Agustus 2016, p-ISSN. 2503-0671, e-ISSN. 2548-5547

\section{Referensi}

Ash, Robert B. 1976. Real Analysis \& Probability. New York : Academic Press Inc.

Bartle, Robert G. \& Sherbert, Donald R. 1992. Introduction To Real Analysis. $2^{\text {nd }}$. ed. New York : John Willey \& Sons.

Bean, Michael A. 2001. Probability: The Science Of Uncertainty With Applications to Investments, Insurance, and Engineering. USA : The Brooks / Cole Series in Advanced Mathematics.

Bhat, B. Ramdas. 1981. Modern Probability Theory. New York : John Willey \& Sons.

Feller, William.1977. An Introduction To Probability Theory and Itl's Applications. New Delhi : Willey Eastern Limited.

Gaskill, Herbert S. \& Narayanaswami, P. P. 1998. Element Of Real Analysis. USA : Prentice Hall.

Hogg, Robert V. \& Craig, Allen T. 1995. Introduction to Mathematical Statistics. $4^{\text {th }}$. ed. New york : Macmilan Publishing Co., Inc.

Laha,R.G \& Rohatgi, V.K. 1979. Probability Theory. New York : John Willey \& Sons.

Walpole, Ronald E. \& Freund, John E. 1987. Mathematical Statistics . $4^{\text {th }}$. ed. New York : Prentice Hall. 